\title{
RIGLYNE VIR DIE VERPLEEGKUNDIGE VIR DIE BIED VAN ONDERSTEUNING AAN ' $N$ GESIN VAN 'N PASIËNT IN 'N ONKOLOGIESE EENHEID OF TUIS: DEEL II
}

\author{
IL Dippenaar en M Greeff
}

\begin{abstract}
OPSOMMING
Wanneer ' $n$ lid yan 'n gesin met kanker gediognoseer word, ward ekstra druk en eise op die gesinsisteem geplaas. Sekere temas kom by die gesin voor, namate hulle die situasie ervad en op hul ete wyse hanteer. Die hooftema by die gesin is die belewing van geestesongemak, ' $n$ Wyse van hantering van sulke geestesongemak is psigiatriese verpleegkundige begeleiding, dewr die psigiariese verpleegspesialis. Soos wat die gesin deur die prosesna aanvaarding beweeg, kom spesiffeke behoefies voor, wat met' $n$ langtermyn benadering deur middel van ondersteuning, angespreek moet word. Deurdat die getalle van psigiatriese verpleegspesialiste min is, berus die ondersteuning aan die pasient en sy gestn hoofsaaklik op die verpleegkundige wat met die gesinne werk.
\end{abstract}

\section{SUMMARY}

Whenever cancer is diagnosed in a member of a family additional pressure and demands are placed on the family system. Certain issues occur in the family to the extent that they experience their situation and cope with it in their own way. The family's main concern is their experience of mentat discomfort. One way of coping with this is by submitting to psychiatric nursing accompaniment tendered by a psychiatric nursing specialist. As the family proceeds to acceptance, specific needs occur, which should be addressed by means of a long-term approach of support. This suppart rests mainly with the registered nurse who works with the family, since the number of trained psychiatric nursing specialists available is smalt.

\section{INLEIDING}

In Deel $\mathrm{l}$ is ' $\mathrm{n}$ oorsig van die probleemstelling, doelstellings, navorsingsontwerp, navorsingsmetode, literatuuroorsig en die resultate en gevolgtrekkings van die studie gegee. Vervolgens word vanuit die navorsing riglyne aan die verpleegkundige gestel vir die ondersteuning van die gesin van 'n pasient in 'n onkologiese eenheid of tuis.

\section{RIGLYNE}

Die literatuuroorsig sowel as die bevindinge van die ingesamelde data het die stel van riglyne aan die verpleegkundige gerig.

Tydens die ondersteuning van die gesin van 'n lid wat met kanker gediagnoseer is, is dit vir die verpleegkundige nodig om van haar teoretiese kennis sowel as haar professionele vaardighede gebruik te maak, ten einde omvattende verpleging aan die pasient en sy gesin te bied. Daar sal kortliks verwys word na die kennisinhoud wat nodig sal wees vir die hantering van die teikengesin, voordat bree riglyne ten opsigte van die praktiese aspekte van die hantering van die gesin uiteengesit word.

\section{Kennisinhoud}

Kennis ten opsigte van die siekte, die invloed daarvan op die pasient en sy gesin, hul reaksies en hantering daarvan, die dinamika van gesinne, selfkennis van die verpleegkundige en verwysingsbronne, sal kortliks bespreek word.

- Kennis ten opsigte van die sieke Die verpleegkundige moet 'n teoretiese grondslag he ten opsigte van die tipes kanker, hul verloop, die behandeling en prognose. Daardeur sal sy die nodige voorligting aan die gesin volgens hul behoefte kan bied, en ook help om bygelowe, wanopvattings en mites sowel as onsekerheid van die gesin uit die weg help ruim.

- Kennis ten opsigte van die invloed van die kankersituasie op die pasient en sy gesin. hul reaksies en hantering daarvan Die verpleegkundige moet kennis ten opsigte van bogenoemde besit, om 'n groter mate van begrip teenoor die pasient en sy gesin te toon. Daardeur sal sy in staat wees om 'n omvattende beraming van die pasient en sy gesin ten opsigte van al hul behoeftes in hul interne en eksterne omgewing, sowel as die interaksie daartussen, te doen.

- Kennis ten opsigte van die dinamika van gesinne

Die verpleegkundige moet bewus wees van moontlike dinamika wat in die gesin na vore kan kom. Sy moet voorbereid wees om, wanneer die gesin daarvoor gereed is, die dinamika aan hulle uit te lig, om so die gesin te lei tot die verkryging van perspektief en kognitiewe en emosionele helderheid.

- Selfkennis van die verpleegkundige

Die verpleegkundige moet bewus wees van die invloed wat die kankersituasie op haar as persoon kan he. Sy moet bewus wees van haar eie emosionele kwesbaarheid, veral waar die pasient en sy gesin hul emosies op haar projekteer.

- Kennis ten opsigte van verwysingsbronne Die verpleegkundige moet kennis he van wat haar rol en funksie is, asook wat haar eie beperkinge in die hantering van die onkologiese pasient en sy gesin is. Dit sal daartoe bydra dat die verpleegkundige nie sal skroom om die gesin na ' $n$ ander lid van die multiprofessionele span te verwys nie. Sy moet voortdurend op hoogte wees van hulpbronne in die gemeenskap waarvan die verpleegkundige, sowel as die gesin kan gebruik maak.

Bree riglyne ten opsigte van die praktiese aspekte van hantering

Temas wat by die pasient en sy gesin tydens hulle ervaring van geestesongemak na vore kan kom, sal by die stel van riglyne genoem word. Die vaardighede waarvan die verpleegkundige tydens haar hantering van die gesin gebruik kan maak, word by die bespreking van riglyne ingesluit.

\section{Fase van die siekte}

- Daar moet so vroeg moontlik met die 
deurwerk van gevoelens en omstandighede van die gesin begin word, indien moontlik, voordat die pasient se toestand so verswak het dat hy dit moeilik vind om aktief aan die interaksie deel te neem.

- Kies die tydsaspek wat vir die pasiënt die mees geleë is, soos byvoorbeeld na 'n rusperiode.

- Skep geleentheid vir die pasiënt om sy gevoelens ook individucel met die verpleegkundige deur te werk wanneer hy gereed voel en nie te moeg is nie.

- Sorg dat die pasient se pyn onder kontrole bly.

- Beraam die pasiënt ten opsigte van sy slaappatroon, sodat daar vasgestel kan word of hy dit as hanteringsmeganisme gebruik wanneer daar as gesin saam gesels word, en of dit as gevolg van 'n verswakte fisieke toestand is.

\section{Onverwerkte krisisse wat by die gesin kan voorkom}

- Begin die deurwerk van die krisis so gou moontlik na die ontwikkeling daarvan, omdat dit van kardinale belang vir die gesin is om die impak daarvan op hulle te beperk. verligting van intense emosies te versnel en die ontwikkeling van patologiese patrone te voorkom.

- Krisistussentrede met die gesin is nodig om die aanvanklike en oorweldigende gevoelens en skok met die gesin deur te werk, hul ondersteuningsbronne te mobiliseer en hanteringsmeganismes te verbeter. Dit is nodig dat die gesin as geheel, sowel as die individuele lede beraam word, direk na die diagnose van kanker, of na die nuus van metastase of ' $n$ swak prognose.

- Opvolgberaming moet gedoen word waar daar na die aanvanklike ontvangs van die nuus, vertraagde reaksie getoon word.

\section{Rou en ander emosies wat beleef word}

- Verliese wat die gesin ervaar, moet met hulle deurgewerk word, sodat hulle ondersteun kan word in die proses van aanvaarding. Die verpleegkundige moet op 'n deurlopende basis die gesin obseveer vir reaksies en tekens van rou, soos insomnia, verminderde eetlus, moeilike konsentrasie, gebrek aan belangstelling in aktiwiteite en die lewe, onttrekking, apatie en angstigheid.

- Waar daar woede en opstand teenoor God voorkom, en die verpleegkundige onveilig voel om die aspekte van die gesin se reaksies self aan te spreek, moet die gesin vir pastorale berading verwys word.

- Observeer die gesinslede ten opsigte van die voorkoms van verplasing en projektering van woede en ander gevoelens op die ander gesinslede of teenoor die personeel.

- Die verpleegkundige kan die manier/wyse van uitdrukking van gevoelens met die gesin bespreek en so taboes ten opsigte van die uitdrukking en belewing van gevoelens met die gesin bespreek. 'n Voorbeeld is dat baie gesinne glo dat jy nie vir God kwaad mag wees en in opstand teenoor Hom mag kom nie.

- Alternatiewe wyses van uitdrukking en uitlewing van gevoelens kan aan die gesin voorgehou word, soos om 'n brief te skryf.

- Evalueer die emosionele toestand van die pasient en ander gesinslede deurlopend, omrede dit voortdurend wissel.

- Tydens die hantering van die gesin se rou en ander emosies wat deur hulle beleef word, is dit nodig dat die verpleegkundige van haar terapeutiese kommunikasietegnieke, professionele vaardighede, eienskappe en houdings gebruik maak om die gesin in hul belewing te ondersteun en hulle die geleentheid vir ventilering te bied.

- Die proses van sterwensbegeleiding moet, waar nodig, met die betrokke gesin deurgewerk word.

\section{Gebrek aan sin en betekenis in die gesitueerdheid}

- Die gebrek aan sin en betekenis wat die gesin in hul gesitueerdheid beleef, moet aangespreek word. Die gesin moet na die verkryging van sin en betekenis in hul omstandighede gelei word deur:

- die geleentheid vir ventilering aan die gesin te bied ten opsigte van hul ervaring van verlies aan sin en betekenis in hul gesitueerdheid.

- saam met die gesin ondersoek in te stel na moontlike sin en betekenis wat die siekte en lyding vir hulle as gesin kan inhou en daar te wees vir hulle terwyl hulle ondersoek instel.

- die gesin na pastorale berading te verwys wanneer die verpleegkundige self onseker voel hoe om die aspek met die gesin deur te werk.

- die gesin aktief te betrek by die behandeling en sorg van die pasient, sodat hulle voel dat hulle iets uit die situasie kan leer, soos hoe om mekaar by te staan en te ondersteun.

- die moontlike doel van kanker en lyding met die gesin uit te klaar (mites en gelowe kan so uit die weg geruim word).
Die langdurige en aanhoudende gebruikmaking van verdedigingsmeganismes

- Werk volgens die gesin se eie tempo en gereedheid na aanvaarding van die rouproses. Laat die gesin dus die pas aangee.

- Die verpleegkundige moet beskikbaar wees vir die gesin wanneer hulle die behoefte aan ventilering het en meer gereed is om met hul gevoelens gekonfronteer te word.

- Die verpleegkundige moet nie direkte druk op die gesin plaas deur hulle op so ' $n$ wyse te konfronteer dat hulleprivaatheid oortree word en hulle daardeur hulle behoud van selfbeskerming verloor nie. Die gesin moet dus voortdurend geobserveer word, vir wanneer gereedheid ontwikkel om hul gevoelens aan te spreek, soos wanneer hulle hul skanse begin afbreek, meer openlik hul emosies erken en minder verdedigend optree, (soos minder ontkenning $v$ an hul omstandighede en gevoelens) en erkenning en later aanvaarding van die realiteit van hul situasie.

- Die gesin kan wel vir terapie verwys word indien die siektetoestand dit toelaat (wanneer die siekte dus nie pre-terminaal of terminaal is nie), en die gesin toestemming daarvoor gee.

Weerstand wat gebied word om openlik met mekaar oor hul omstandighede en gevoelens te praat

- Bou 'n vertrouensverhouding met die gesin op, voordat daar met die aktiewe deurwerk van hul gevoelens begin word.

- Dikwels wil die gesinslede nie met mekaar oor hul omstandighede en gevoelens praat nie, omrede hulle bang is dat hulle mekaar sal ontstel of dalk self ontsteld sal raak. In sulke gevalle kan gevoelens eers individueel met die gesinslede deurgewerk word, sodat elkeen meer tot aanvaarding van sy eie gevoelens kom en dit self deurwerk. Die gesinslede sal daama met meer gemak en vertroudheid met mekaar oor hul omstandighede en gevoelens kan praat en die verpleegkundige kan dan die gesin gesamentlik verder ondersteun en kommunikasie tussen hulle aanmoedig en bevorder. Sodoende sal sy ook die isolasiegevoel van die gesinslede aanspreek.

\section{Ervaring wan verlies aan beheer en kontrole}

- Betrek die gesin aktief by die versorging en behandeling van hul geliefde, sodat hulle hulpeloosheidsgevoel verminder kan word deurdat hulle voel dat hulle iets kan bydra om hul situasie makliker en ligter vir mekaar te maak. 
- Bied praktiese leiding ten opsigte van hoe die gesinslede hul geliefde kan help versorg.

- Moedig die pasient aan tot deelname aan selfsorg en gee die nodige onderrig en voorligting.

- Betrek die gesin by deelname aan besluitneming

- Skep geleenthede waar die pasient en sy gesin aktiwiteite kan volhou, byvoorbeeld uitstappies, en nooi hulle uit na aktiwiteite wat in die eenheid of in die gemeenskap gehou word.

- Moedig die pasient en sy gesin aan om aktiwiteite van vroeer te hervat en vol te hou daarmee.

- Konsulteer 'n arbeidsterapeut om 'n verskeidenheid aktiwiteite aan die pasient voor te houveral wanneer hy bedleend is, of sy bewegings beperk is.

- Gee voorligting aan die pasient en sy gesin ten opsigte van pynbeheer, byvoorbeeld die toediening van medikasie en die gebruik van tegnieke wat aangeleer kan word om pyn te verminder.

- Klaar wanidees en wanopvattings ten opsigte van kanker en die verloop daarvan wat onsekerheid kan vererger met die gesin uit.

- Fasiliteer ondersteunings- en selfhelpgroepe, waar die pasiënt en sy gesin aangemoedig word om aan selfsorg deel te neem en waar hulle na ander kan vitreik en ondersteuning aanbied.

Die verpleegkundige spreek deur bogenoemde optredes die moontlike onttrekking van gesinslede aan, verminder hul gevoel van verlies aan beheer en kontrole, sowel as hul gevoel van isolasie, en verminder daardeur hul ervaring van geestesongemak.

\section{Gevoel van isolasie wat beleef word en geestesongemak vererger}

- Spreek die gevoel van isolasie (wat dikwels met die gevoel van verlies aan beheer en kontrole gepaard gaan) aan dit gevoel individueel of in 'n groep te bespreek, waar die pasient sy ervaring met ander kan deel. Klem kan gele word op die feit dat die gevoelens van isolasie, verlies aan beheer en kontrole en dus hul ervaring van geestesongemak, nie deur ander waarneembaar is nie, en dat elkeen sy situasie oenskynlik goed hanteer.

- Klaar die gesin se verwagtinge wat hulle van mekaar het uit, sowel as die teenoor die personeel. Maak die gesin daardeur bewus van hul behoeftes, en hoe hulle mekaar kan help, bystaan en ondersteun.
Onsekerheid ten opsigte van omstandighede en die toekoms weens die siekte

- Die verpleegkundige moet voorligting aan die gesin bied ten opsigte van die siekte en behandeling, om daardeur die onsekerheid wat deur die pasient en sy gesin beleef word, aan te spreek en wanidees wat onsekerheid $k$ an vermeerder uit die weg te ruim. Dit kan gedoen word deur middel van praatjies, video's, boeke, pamflette, seminare en groepe, soos die "Ek kan oorwin"-programme. Voorligting wat die verpleegkundige aan die gesin moet bied, is ten opsigte van die fisieke, psigiese, sosiale en finansiele implikasies van die siekte en behandeling. Daardeur berei sy die gesin voor vir wat hulle te wagte kan wees, al is dit vir 'n kort termyn.

- Stolling van die toekomsverwagtinge by die gesin kom dikwels as gevolg van die onsekerheid voor en die gesin leef op 'n dag-vir-dag basis.

- Die verpleegkundige moet ook aan die gesin die geleentheid vir ventilering van hul onsekerheid bied en sy moet beskikbaar wees vir vrae deur die gesin.

- Die gesin moet aangemoedig en ondersteun word om korttermyn doelwitte wat realisties en bereikbaar is, te stel, al is dit op 'n daaglikse basis. Daardeur bevorder die verpleegkundige die gesin se self waarde omdat hulle voel dat hulle vir iets werk en wel as gesin saam iets kan bereik (al is dit op 'n dag-vir-dag-basis).

\section{Rolveranderinge}

- Werk die verlies wal die pasient ervaar ten opsigte van die prysgee van 'n rolfunksie, met hom deur.

- Geleentheid moet aan die gesin gegee word om hul ervaringe rondom die aanpassing by nuwe rolle en die verhoogde druk en nuwe eise wat dit veroorsaak, te deel, sodat hul gevoelens daaromtrent met hulle deurgewerk kan word.

- Die verpleegkundige moet so vroeg moontlik in die siekteverloop die gesin voorberei op die moontlike verandering van rolle en take, as gevolg van die eise wat die siekte stel. Wanneer die pasient gehospitaliseer is of wanneer sy fisieke toestand dit vereis dat sy take tuis verminder moet word, moet die verpleegkundige aspekte soos rol- en taakverdeling met die gesin bespreek.

\section{Behoefte aan die verandering van hanteringsmeganismes}

- Die behoefte sal hoofsaaklik deur die psigiatriese verpleegspesialis tydens psigiatriese verpleegkundige begeleiding aangespreek word. Sy moet egter vaardig wees met die psigiatriese verpleegkundige begeleidingsproses.
- Waar 'n plato-fase deur die gesin bereik word, sal dit nodig wees om eers deur die gevoelens en omstandighede van die gesinslede te werk, en verdedigingsmeganismes soos die ontkenning van gevoelens en onttrekking van mekaar, volgens die gesin se gereedheid af te breek voor die gesin se verandering van hul hanteringsmega- nismes aangespreek word. Hulle moet dus gereed gemaak word om met mekaar oor hul gevoelens en omstandighede te praat. Wanneer die gesin nie hul gevoelens en omstandighede in 'n mate aanvaar het nie, sal dit vir hulle ook moeilik wees om dit te erken en openlik met mekaar daaroor te praat.

- Die gesin se huidige hanterings meganismes moet geevalueer word en daar moet saam met hulle na alternatiewe hanteringsmeganismes gesoek word Individuele beraming van gesinne is van belang en die behoefte moet volgens die bepaalde gesin aangespreek word. Dit kan nodig wees dat konkrete aspekte van die gesin se hantering eers aangespreek moet word, omdat dit minder bedreiging vir die gesin inhou. Daarna kan die gesin se hantering ten opsigte van gevoelsaspekte, soos meer openlike kommunikasie oor hul omstandighede en gevoelens, met hulle deurgewerk word.

- Spreek verdedigingsmeganismes aan deur middel van interpreterende konfrontasie. om die gesin daardeur na kognitiewe en emosionele opklaring en -helderheid te lei.

- Alternatiewe hanteringsmeganismes kan wel aan die gesin voorgehou word, maar die keuse en verantwoordelikheid berus by hulle om dit te ondersoek, te toets en die keuse te maak van wat hulle bereid is om te internaliseer.

\section{Behoefte aan langtermyn ondersteuning}

- 'n Langtermyn benadering en verhouding met die gesin is nodig om in die behoeftes van die gesin te voldoen. Die verpleegkundige moet so vroeg moontlik na die diagnose kontak maak met die pasient en sy gesin en dit deur die hele verloop van die siekte met hulle behou. Die gesin moet op 'n deurlopende basis beraam word, om spesifieke fases waarin hulle beweeg, en die gepaardgaande behoeftes tydens die fases, te identifiseer.

- Spreek die behoeftes van die gesin aan teen hul eie tempo en gereedheid. Die verpleegkundige moet daarom 'n oopheid toon vir die uitspreek van behoeftes deur die gesin, en vir hulle beskikbaar wees.

\section{Behoefte aan opvolging}

- Opvolgondersteuning ook na die afsterwe $v$ an die pasient is nodig en 'n nuwe beraming van die gesin kan gemaak word. Hulle kan makliker met die res van hul lewens voortgaan, omdat daar nie meet 'n 
stolfaktor ten opsigte van die toekoms teenwoordig is nie.

Die volgende opsomming is gemaak ten opsigte van die hantering van die gesin deur die verpleegkundige:

- Langtermyn gesinsondersteuning, waar die verpleegkundige die gevoelens en omstandighede van die gesin as geheel met hulle deurwerk en hulle daarin ondersteun.

- Indien die gesin die behoefte uitspreek vir die verandering van hul hanteringsmeganismes, en daar deur die aanvanklike krisistydperk gewerk is, kan die gesin vir psigiatriese verpleegkundige begeleiding na die psigiatriese verpleegspesialis verwys word.

- Die verwysing van die gesin vir gesinsterapie, waar hulle betredend gekonfronteer word, op voorwaarde dat die pasient nie pre-terminaal of terminaal siek is nie, en dat die gesin toestemming gee vir die oortreding van hul privaatheid.

- Individuele onderhoude met die gesinslede wat deur individuele behoeftes in die gesin bepaal word. (Die kans is sodoende kleiner dat daar 'n blokkering van die ander lede voorkom as die individuele lid nie sy behoeftes en gevoelens wil uitspreek nie.) Die ervaring en gevoelens kan moontlik vinniger individueel deurgewerk word voordat die hele gesin as geheel gesien word.

- Subsisteme in die gesin kan saam gesien word, soos ouers op hul eie en die kinders as 'n groep. Behoeftes en interpretasie tussen die subsisteme kan verskil en die ouers wil dalk nie aan die kinders openlik hul eie gevoelens en omstandighede erken nie - die idee dat die ouer die voorbeeld moet stel van die "sterk" persoon en dat hy altyd in beheer van omstandighede moet bly. Die ouers wil ook dikwels nie die kinders omtrent die realiteit inlig nie, omdat hulle "nie sal verstaan nie".

\section{SLOTSOM}

Uit hierdie studie is dit duidelik dat die gesin van 'n pasient wat kanker het, langtermyn ondersteuning nodig het, vanwee die voortdurende druk en eise wat die siektetoestand veroorsaak. Dit is belangrik dat die verpleegkundiges wat met die gesinne werksaam is, nie net bewus moet wees van die impak wat die kankersituasie op die gesin het nie, maar ook paraat moet wees om die gesin as geheel te ondersteun, om daardeur hul geestesongemak te verminder en so hul strewe na heelheid te maksimeer.

\section{VERWYSINGS}

Ahmed, P (1981): Coping with medical issues. Living and dying with cancer. New York: Elsevier.

Baird, SB (1988): Decisionmaking in oncology nursing. Toronto: B.C. Decker.

Cahoon, MC (1982): Cancer nursing. Edinburgh: Churchill Livingstone.

Capra, LG (1972): The care of the cancer patient. London: William Heinemann.

Capra, LG (1986): Care of the cancer patient; Second Edition. London: Macmillan.

Chadwick, BA; Bahr, HM \& Albrecht, SL (1984): Social science research methods. New Jersey: Prentice-Hall

Chesler, MA \& Barbarin, OA (1987): Childhood cancer and the family: Meeting the challenge of stress and support. New York: Brunner/Mazel.

De Villiers, FMJ (1985): Sterwensbegeleiding in Christelike perspektief. Pretoria: NG Kerkboekhandel.

Dlppenaar, IL (1993): Psigiatriese verpleegkundige begeleiding aan 'n gesin van ' pasient in 'n onkologiese eenheid. Johannesburg: Randse Afrikaanse Universiteit (M.CUR -skripsie)

Donovan, MI \& Pierce, SG (1976): Cancer care nursing. New York: Appleton-Century-Crofts.

Goldberg, RJ \& Tull, RM (1983): The psychosocial dimensions of cancer. A practical guide for health care providers. New York: The Free Press.

Gonda, TA \& Ruark, JE (1984): Dying dignified. The health professional's guide to care. Califomia: Addison-Wesley.

Greeff, M (1991): 'n Model vir psigiatriese verpleegkundige begeleiding van die pasient met geestesongemak. Johannesburg: Randse Afrikaanse Universiteit (D.Cur.-proefskrif)

Holland, JC \& Rowland, JH (1989): Handbook of psycho-oncology. Psychological care of the patient with cancer. New York: Oxford University Press.

Lokich, JJ (1978): Primer of cancer management. Boston: Martinus Nijhoff Medical Division.
McIntosh, J (1977): Communication and awareness in a cancer ward. London: Croom Helm.

ORAL ROBERTS UNIVERSITY ANNA VAUGHN SCHOOL OF NURSING (1990): Self Study Report, submitted to the Council of Baccalaureate and Higher Degree Programs, National League of Nursing, August 1990 Volume 1 - Narrative by Criteria. Tulsa, Oklahoma: Oral Roberts University Anna Vaughn School of Nursing.

RANDSE AFRIKAANSE UNIVERSITEIT DEPARTEMENT VERPLEEGKUNDE SEPTEMBER (1992): Verplegingsteorie vir Mensheelheid. Johannesburg: Randse Afrikaanse Universiteit. pp. 1-42.

Rosenbaum, EH (1980): A comprehensive guide for cancer patients and theirfamilies. California: Bull.

Sims, $S$ (1989): Hope and coping with cancer Verpleging RSA, 4(4), 33-39.

Smith, JP (1991): Meeting the challenge of cancer care and prevention in Europe. Journal of Advanced Nursing, 16(11), 1267-1268.

TIffany, R (1980): Oncology for nurses and health care professionals; Volume 2: Care and support. London: George Allen \& Unwin.

Ventafridda, V \& Van Dam, FSAM (1986): Assessment of quality of life and cancer treatment. Proceedings of the international workshop on quality of life assessment and cancertreatment. Amsterdam: Ex cerpta medica.

Weisman, AD (1979): Coping with cancer. New York: McGraw-Hill.

Wong, CA \& Bromwell, L (1992): Uncertainty and anxiety after mastectomy for breast cancer. Cancer Nursing, 15(5), 369-370.

Woods, NF \& Catamzaro, M (1988): Nursing research. Theory and Practice. St. Louis: C.V. Mosby.

Yin, RK (1989): Case study research, design and methods. Applied sosial research methods series; Volume 5; Second Edition. London: Sage.

I.L. Dippenaar

M.CUR. Psigiatriese Verpleegkunde RAU Departement Verpleegkunde

$M$ Greeff

D.CUR. Psigiatriese Verpleegkunde Professor: Verpleegkunde $\mathrm{PU}$ vir $\mathrm{CHO}$ 